\title{
Welcome Messages from the Congress Presidents
}

\section{My dear friends and colleagues,}

\section{IRRASHAI!!! WELCOME!!!!}

It is my enormous pleasure and indeed honour to welcome you to Laser Tokyo 2009, the banner under which the $18^{\text {th }}$ International Society for Laser Surgery and Medicine, the 2nd World Federation of Societies for Laser Medicine and Surgery and the $30^{\text {th }}$ Japan Society for Laser Surgery and Medicine congresses are being held as a joint meeting. When I was first entrusted with holding the ISLSM meeting not even a year ago, and decided to hold it as a joint meeting with the WFSLMS and JSLSM, it seemed that there was plenty of time to get everything organized in collaboration with my fellow presidents, Professor Krishna Rau of the WFSLMS and Professor Kikuchi of the JSLSM; but of course, time has a way of running through a congress president's fingers like fine sand, and suddenly, here we all are! However, I have no hesitation in welcoming you to Laser Tokyo 2009, because we have a superb line up for you which should satisfy everyone, both from the scientific body of the very full pro-

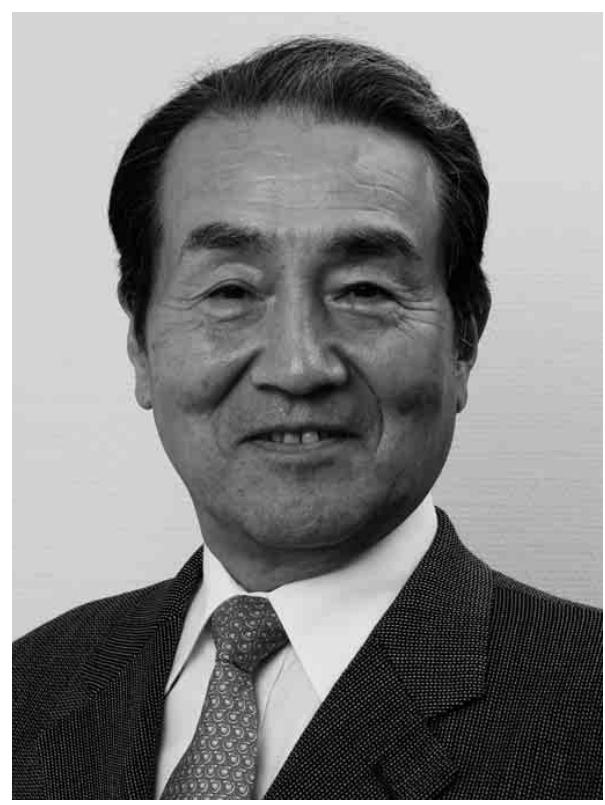
gramme, and from the aspect of the social programme: after all you are in Japan, the country where we really 'work hard and play hard', so let me assure you, you will be doing both of these!! The first word of Japanese to help you fulfil the "play hard' part is 'kampai, which means 'cheers' or actually quite literally, 'bottoms up'! Please learn it because I think you will be using it a lot!! The scientific programme could not be fuller, as you will see from the Programme-at-a-Glance, and we have a superb collection of plenary, special and invited lectures in addition to the very full symposium programme, so much so for the latter that we are running many parallel session so you will need to mark in advance the talks you want to attend!

As for the social programme, I am sure you are all really looking forward to our exciting and sumptuous Tokyo Bay Cruise, not to mention the Welcome Party and the joint Presidents' Banquet in the congress hotel. Of course we must not forget where the congress is being held: in the city of Edo, the ancient name for Tokyo, where ultramodern rubs shoulders comfortably with ancient tradition. You can walk along a glittering street in the Ginza, Tokyo's Mecca for shopaholics, yet take any one of the many small streets which lead of the main Ginza-dori (Ginza avenue) and you will find even smaller alleyways filled with old-style eateries where you can enjoy some of our traditional foods in traditional surroundings.

We must also always remember that our congress is also a forum for the industry: laser manufacturers, equipment specialists and medical publishers. Please take time to see 'what's hot' in the world of laser surgery and medicine hardware, software and pharmaceuticals, and spend time with the exhibitors. We have events going on in and around the exhibit area, so please participate, and show support for the exhibitors who are here to share their knowledge with you of the latest technology, ancillary equipment, pharmaceuticals and literature.

So, dear friends and colleagues, on behalf of myself and my colleagues, I sincerely hope that you will make the most of your stay here. It is very true that the more you put into something the more you will get out of it, and that is essentially true for our Laser Tokyo 2009 extravaganza. I urge you to: make new friendships and cement old ones; consolidate your existing knowledge of laser surgery and medicine, and add new nuggets of knowledge straight from the leading international experts, and of course, work hard, play hard!

Finally, thank you from the bottom of my heart for being here, joining us, and reading this message. There can be no congress without the attendees!

\section{Toshio Ohshiro}

Toshio Ohshiro

President of $18^{\text {th }}$ Congress of ISLSM 


\section{Dear Colleagues in Laser,}

It is an honor and pleasure to welcome you for the LASER TOKYO 2009 so well organized by Prof. Ohshiro and Prof Kikuchi.

The World Federation of Laser Societies conceived and formed at the 2001 meeting of ISLSM in Chennai with Prof Atsumi as Founder President and Prof. Ohshiro as Founder Secretary General, have in the last eight years done extra ordinary work to fulfill the aims and objectives of the Society. To bring together the Laser Societies in different parts of the world to come and discuss the current and future course of laser application in medicine and surgery , research in the development of newer laser wave lengths, and dissemination of the work done and publish the results of work done around the world in the Official Journal of our society.

The important decision to conduct courses in laser, followed by examinations and issue certificate of compe-

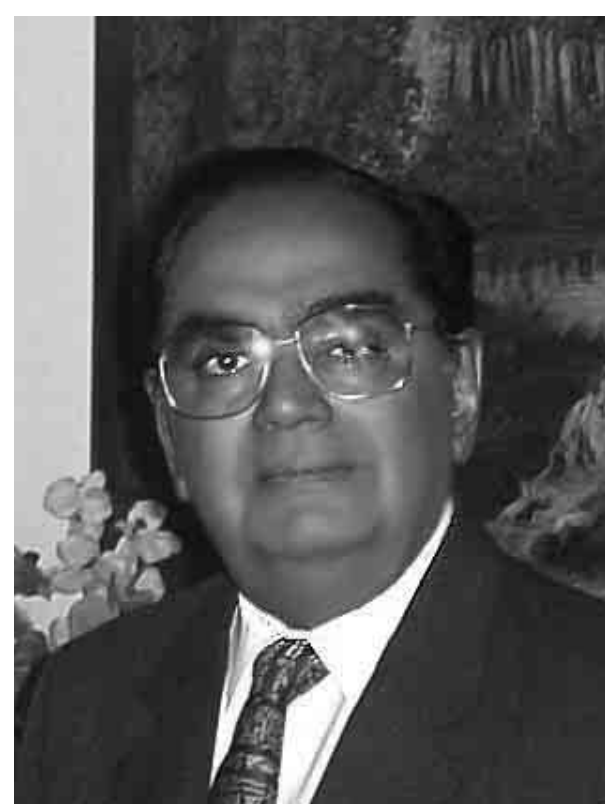
tence at various levels, will be the hall mark of this congress. This certification, the first in history of laser, will enable laser specialists to be graded at international standards.

The formation of KAAPA foundation and B-SAC are important land marks of our association. Prof. Atsumi and Prof. Ohshiro have laid solid foundation of WFSLMS. LASER TOKYO 2009 meeting will consolidate the past achievements and chart out the goals for the next four years. I join with the Presidents Prof. Ohshiro of ISLSM and Prof. Kikuchi of JSLSM, in extending our warm invitation to attend the memorable meeting both in terms of scientific content and the hospitality laid out by the Organising Committee.

I look forward to meeting you in Tokyo

With best wishes

\section{B. Krishna Rau}




\section{Welcome to "Laser Tokyo 2009"}

"Laser Tokyo 2009"- the joint congress of 18th International Society for Laser Surgery and Medicine (ISLSM), 2nd World Federation of Societies for Laser Medicine and Surgery (WFSLMS), and $30^{\text {th }}$ Japan Society for Laser Surgery and Medicine (JSLSM) being held in Tokyo, Japan, on November $29^{\text {th }}$ - December $3^{\text {rd }}, 2009$, is the world's leading congress for presenting the results of current scientific work in health-related laser application to an international audience. We would like to invite you to attend this outstanding scientific event!

In 2009 , the JSLSM celebrates its $30^{\text {th }}$ anniversary which is an extraordinary honor and a huge responsibility for the JSLSM congress president. During "Laser Tokyo 2009" we hold the ceremony and celebration banquet of our $30^{\text {th }}$ anniversary. As we approach our $30^{\text {th }}$ anniversary, the

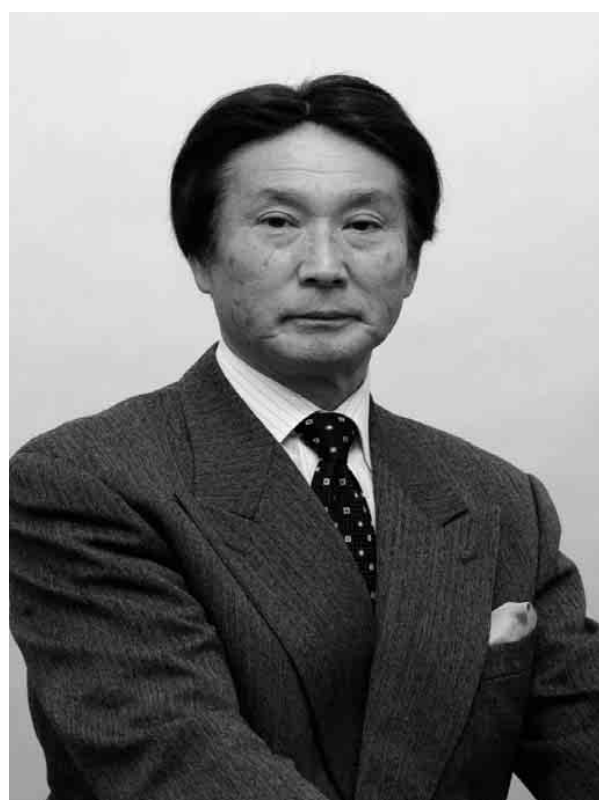
JSLSM's leadership will be challenged to utilize and support its experienced and diverse membership to its optimum potential to meet the many opportunities presented by the field of laser in medicine.

Since the "Laser Tokyo '81" convened in 1981, laser technology oriented physicians and engineers not only from Japan but also all continents have together to discuss how laser technology can advance medicine, health and health care to assess the clinical, scientific, technical and professional progress in their fields. The ultimate purpose of the laser application in medicine must be the delivery of healthcare to our fellow citizens and the achievement of the goal of healthcare for all. Thus the theme of Laser Tokyo 2009 is "Integrative Hybrid Medicine for the New Millennium - the gateway to personalized healthcare delivery".

It gives me great pleasure to welcome you to this important event. I wish you a rewarding and enjoyable congress and a most pleasant time in Tokyo, the "metropolis with heart" that has so much to offer.

\section{Makoto Kikuchi}

